\title{
INSIGHTS INTO INTERNATIONAL PUBLICATION: A SYNTHESIS OF MOVE-BASED LITERATURE ON THE RESEARCH ARTICLE GENRE
}

\author{
Ton Nu My Nhat* \\ Department of Foreign Languages, Quy Nhon University \\ 170 An Duong Vuong, Quy Nhon, Binh Dinh, Vietnam
}

Received 21 September 2018

Revised 25 January 2019; Accepted 29 January 2019

\begin{abstract}
Ever since Swales' (1981/1990) work on the research article (RA), this genre has been subject to copious investigation in the past three decades. This attraction is due to both its highly valued status as a means of disseminating academic knowledge and the high pressure on part of the university staff and $\mathrm{PhD}$ students to have publications in international journals in many countries where English is not a native language. This paper reviews the literature on genre/move-based investigations into writing for international publication. The three areas of focus are the rhetorical structures, the linguistics features, and the cross-cultural comparisons of these two aspects. The synthesis provides a detailed account of both consistencies and inconsistencies to the conventional structures, as well as of the similarities and differences in the linguistic realizations, across various disciplines and cultures. ${ }^{* *}$
\end{abstract}

Keywords: research article, genre analysis, move analysis, international publication

\section{Introduction}

As a widely used genre of building and disseminating academic knowledge, research article (RA) is one of the most important genres in academic communities. RA is considered "key medium for the legitimating of claims and of disciplines" (Hyland, 1996: 252). Swales (1990: 7) states, "publication can be seen as documentary evidence that the writer qualifies for membership in the target discourse community". However, writing a

\footnotetext{
* Tel.: 84-905242270

Email: tnmynhat70@gmail.com

** The paper was revised carefully on the basis of the report which was presented at $4^{\text {th }}$ International Conference Interdisciplinary Research in Linguistics and Language Education, Hue City, October 2018.
}

$\mathrm{RA}$ is a formidable endeavor as it requires scholars to be knowledgeable to establish the importance of their research and to be familiar with the presentation norms of their discourse communities. As Lim (2006) noted, "RAs are generally considered a genre that embodies stringent academic requirements in terms of both textual organization and linguistic choices".

Despite the many inherent challenges of writing RAs, and given the "AngloAmerican dominated scientific discourse community" (Li, 2007), non-Anglophone scholars have been increasingly pressured to publish in international journals. With the aim of promoting the country's share of global research output, the academic evaluation systems in many countries have 
imposed policies to promote publications in international journals. The publication of RAs in international journals, particularly those indexed in the ISI-Web of Science, has been a major criterion for evaluating the academic performance of university staff. For graduate students, particularly at the doctoral level, publication in specialist English-medium journals is also set as a graduation requirement in multiple universities in many non-native English speaking (NNES) countries, such as China, Taiwan, Japan, or Turkey (Huang, 2010, 2014; Is1k-Tas, 2018; Li, 2007). For instance, very recently, in line with these policies, Vietnam has issued a centralized criterion for academic promotion in 2018 which dictates a minimum of two and three RAs published in a prestigious, established international journal as one of several requirements for promotion to associate professor and professor, respectively, in all disciplines.

In response to these pressures and to facilitate the entry of novice NNES scholars to the highly selective academic discourse community, the barriers to successful submission to English-medium journals have been subject to copious investigation. Some researchers (e.g. Flowerdew, 1999; Li, 2007; Huang, 2010, 2014) have noted that it is much more challenging for NNES scholars to get their work published in refereed journals than English native speakers. Ventola's (1992) investigation revealed some of the intercultural challenges facing the Finnish writers such as problems with themerheme patterns, with consistent tracking of participants with reference items, and with the use of various connectors. Through in-depth interviews, Flowerdew (1999) identified a range of problems which confront Hong Kong Chinese scholars in writing for publication in English and which they feel put them at a disadvantage vis-à-vis native speakers of that language. A number of key areas are identified: they have a less rich vocabulary; they find it difficult to make claims for their research with the appropriate amount of force; their process of composition may be influenced by their L1; qualitative articles are more problematic than quantitative articles; they are restricted to a simple style; and the introductions and discussions to scholarly articles are particularly problematic parts. Huang's (2010) study involved eleven PhD/ Post Doc students and three professors who came from eight disciplines and ten academic institutions in Taiwan. Huang investigated their perceptions of publishing and learning to write for publication in English. The findings show that these students regard themselves as disadvantaged due to their limited proficiency in English. In addition, the nonnative Englishspeaking $\mathrm{PhD}$ students' disinclination to learn to write for publication is influenced by many factors other than perceived language incompetence.

Of the works addressing the needs of advanced non-native English speakers who learn to read and write RAs, the most influential work is undoubtedly Swales' (1981, 1990). Later on, Swales' framework was revised by himself (Swales, 2004) and extended by other scholars. Swales' work has had a tremendous influence on the studies on RAs. During the past four decades, research into this genre has flourished, basing on Swales' move-based model. These studies have investigated how the writers organize their RAs to communicate its rhetorical purposes and/or what linguistic features the writers use to realize the communicative purposes. The conventional sections of the RA have been extensively investigated, such as Introduction section (e.g. Ozturk, 2007; Kanoksilapatham, 2011), Methods section 
(e.g. Lim, 2006; Peacock, 2011; Cotos et al, 2017), Results section (e.g. Brett, 1994; Lim, 2011.), Discussion section (e.g. Holmes, 1997; Dobakhi, 2016). Beside the studies which treat each RA section as an independent entity, there is a growing body of research into the complete RAs (e.g. Kwan, 2017; Tessuto, 2015; Fazilatfar \& Naseri, 2014; Nwogu, 1997), across diverse disciplines. Some others, still, adopting a cross-cultural stance, focused on macro- or micro- features of the RA (e.g. Mahzari \& Maftoon, 2016; Elvan \& Is1k-Tas, 2017).

This multi-dimensional area of research over a forty-year span appears to necessitate a detailed synthesis of the existing relevant studies. Drawing on the voluminous literature on genre-based studies, this paper is practically motivated and the aim is twofold. First, as a comprehensive but necessarily concise account of RA, it illuminates the path for those inspired to conduct research into this fruitful genre. Second, as a thorough description of the rhetorical structures and functions and the linguistic characteristics of RA cross disciplines, it is significantly beneficial to novice NNES scholars concerned with writing for international publication.

The remainder of this article is organized as follows. Section 2 will provide an overview of the Swales' two-layered move/step model of the RA. Section 3 will summarize the literature in three main lines - (1) the rhetorical structure, in terms of the organization of the RA in entirety and of the individual sections, as well as combinations of two or three consecutive sections; (2) the linguistic features characteristic of the communicative purposes; and (3) both these areas of concern from a cross-cultural perspective. The last section will conclude the paper with some implications for ESP pedagogy and future research.

\section{Genre analysis and move-based analysis}

Genre is defined as a social practice of using language recognized by a discourse community in which its members engage to mark their membership (Swales, 1990). It is based on the assumptions that the features shared among a group of texts depend on the social context of use, and that those features can be delineated in a way that relates a text to the ones similar and to the constraints acting on the producers (Hyland, 2003). Genre theory is generally referred in three broad schools. The New Rhetoric approach focuses mainly on the rhetorical contexts in which genres are employed. The ESP approach sees genre as a class of structured communicative events used by specific discourse communities whose members share broad social purposes (Swales, 1990: 45-47). A third school, based on Halliday's (1994) Systemic Functional Linguistics (SFL), stresses the purposeful, interactive, and sequential character of different genres and the ways language is systematically linked to context through patterns of lexico-grammatical and rhetorical features (Christie \& Martin, 1997).

Genre analysis (GA) readily lends itself to the pedagogic concerns of those involved in the ESP and EAP classrooms. The rhetorical functions and their linguistic exponents can be purposefully exploited through tasks and materials which directly reflect those texts that learners have to comprehend and produce (Brett, 1994). With generic awareness, ESP students, especially post-graduates, and novice writers can better understand and generate complex genres to be a member of their academic community (Bhatia, 1997; Hyland, 2002). Dudley-Evans (2000) emphasized, "The Moves and Steps that Swales (1990) suggests for the article introduction marries the textual awareness of the register analysts 
with a much broader view of how rhetorical considerations govern grammatical choice. [...]. The interest in discourse community and how the expectations and conventions of different discourse communities mould the texts that they use has led to this broader view and placed ESP research in a position where it can make a meaningful contribution to discussion of how ideas are disseminated and facts created in communities." (DudleyEvans, 2000)

One of the genre-based approaches used to identify the rhetorical schema of RAs is 'move analysis' (Swales, 1981, 1990, 2004). Swales' (1981, 1990, 2004) pioneering work focused on the RA, and in particular the introduction section, known as Creating a
Research Space model (the CARS model) (Table 1). The model consists of three Moves and a number of Steps used to realize express each move. The illustrations of complete introductions in terms of Moves and Steps can be found in Ozturk (2007) or Kanoksilapatham (2011). The model captures the ways in which academic writers justify, highlight, and present their own contribution to the ongoing research profile of the field (Dudley-Evans, 2000) by first establishing the topic, then justifying the present study and finally describing the present study. Swales' seminal model has become a powerful tool in RA analysis because it provides insights into key characteristics of the genre, including the organizational structure as well as linguistic features.

Table 1. Modified CARS by Swales (2004) model

\begin{tabular}{|c|c|c|}
\hline MOVE 1 & \multicolumn{2}{c|}{ ESTABLISHING A TERRITORY } \\
\hline & Step 1-1 & Claiming centrality and/or \\
\hline & Step 1-2 & Making topic generalizations and/or \\
\hline MOVE 2 & Step 1-3 & Reviewing items of previous research \\
\hline & Step 2-1A & ESTABLISHING A NICHE \\
\hline & Step 2-2B & Indicating a gap or \\
\hline & Step 2-2 & Adding to what is known \\
\hline MOVE 3 & & Presenting positive justifications \\
\hline & Step 3-1 & Announcing present research descriptively and/or purposively \\
\hline & Step 3-2 & Presenting RQs or hypotheses \\
\hline & Step 3-3 & Definitional clarifications \\
\hline & Step 3-4 & Summarizing methods \\
\hline & Step 3-5 & Announcing principal outcomes \\
\hline & Step 3-6 & Stating the value of the present research \\
\hline & Step 3-7 & Outlining the structure of the paper \\
\hline
\end{tabular}

The units of analysis are 'Move' and 'Step' (Swales, 1990). A Move is "a discoursal or rhetorical unit that performs a coherent communicative function in written or spoken discourse" (Swales, 2004: 29). It is "a segment of text that is shaped and constrained by a specific communicative function" (Holmes, 1997). Nwogu further 
specifies this semantic unit as "a text segment made up of a bundle of linguistic features (lexical meanings, propositional meanings, illocutionary forces, etc.) which gives the segment a uniform orientation and signals the content of discourse in it" (1997: 114). Pho (2008a) claimed "each move has its own communicative purpose, which, together with other moves, contributes to the general communicative purpose of the text" (p. 17). A Move can be realized by either one Step, which is the rhetorical techniques realizing the function of Move, or a combination of Steps. This two-layer analysis in terms of Move and Step, is seen as a "robust method of genre analysis" as while Move captures the communicative function of a segment of text at a more general level, Step spells out more specifically the means to realizing the rhetorical purpose of Move (Ruiying and Allison, 2003). Ruiying and Allison (2003) clarify, "The set of Steps for a Move is the set of rhetorical choices most commonly available to RA authors to realize a certain purpose. The order of Steps presented in each Move only shows a preferred sequence for the choices to occur when in combination".

Although it was acknowledged that there may be some differences between disciplines, the initial work on Move and Step analysis suggested that the models proposed were generalized and can be applied to RAs in all academic disciplines; actual RAs will vary in the degree to which they conform with these prototypes. What has become clear, still, is that disciplinary variation tends to be highly significant, as will be reviewed in the following sections.

\section{Review of research into the RA genre}

The constraint of an article precludes an all-rounded review of the voluminous literature growing over a span of nearly four decades. This section will therefore address the three most pertinent features - the rhetorical structure and the associated communicative functions, the linguistic features, and these two dimensions from a cross-cultural perspective.

\subsection{Rhetorical structures of RAs}

The growing concern for this important genre has attracted research into its structural and linguistic features of the RA in a very wide range of disciplines. The largest number chose to analyze only the RAs in just one single discipline, such as Agricultural Economics (Holmes, 2000); Applied Linguistics (e.g. Yang \& Allison, 2003, 2004; Ozturk, 2007; Dujsik, 2013; Amnuai \& Wannaruk, 2013; Fazilatfar \& Naseri, 2014; Le \& Harrington, 2015; Dobakhi, 2016); Biochemistry (e.g. Thompson, 1993; Kanoksilapatham, 2005); Biology (Martinez, 2003); Business and economics (Moreno, 1997, 1998); Chemistry (Li, 2007); Civil engineering (Kanoksilapatham, 2011); Computer (Posteguillo, 1998; Ershadi \& Farnia, 2015); Education (Rahman et al, 2012); ELT (Jaroongkhongdach, et al. 012); Environmental studies (Paltridge, 1993); Exercise Physiology (Huang, 2014); Information System (Kwan, 2017); Law (Tessuto, 2015); Management (Lim, 2006); Mathematics (2013 Grave et al); Medicine (Nwogu, 1997; ElMalik \& Nesi, 2008; Li \& Ge, 2009; Mahzari \& Maftoon, 2016); Physics (Parkinson, 2011); Sociology (Brett, 1994; Elvan Eda Is \& ik-Tas, 2017).

The systematic and detailed investigations into the rhetorical structure of most studies have yielded the move/step schemas models for the disciplines in focus, such as Samraj's (2002) model of Introduction section, Cotos et al's (2017) model of Methods section, Brett's (1994), Tessuto's (2015), and Thompson's 
(1993) models of Results section, Peacock's (2002), Dobakhti's (2016), Yang \& Allison's (2003) models of Discussions section, and Nwogu's (1997), Kanoksilapatham's (2005), and Pho's (2008a) models of the whole RA, in a number of disciplines. For instance, Kanoksilapatham (2005) reports on the results of a move analysis of 60 biochemistry RAs and proposed a two-level rhetorical structure consisting of 15 distinct moves: three moves for the Introduction section, four for the Methods section, four for the Results section, and four for the Discussion section. The Moves and Steps in these models are also specified in terms of obligatory status. For example, in his study of the structure of medical RAs, Nwogu (1997) examined the whole body of 15 medical RAs from five authoritative medical journals. He developed a schema of 11 moves, eight of which he described as "normally required" (also known as "obligatory") and three of which as "optional". The "obligatory" moves constitute the limits of a genre and give a pattern of communication its identity, without which a genre would lose its integrity, while the "optional" moves are available choices authors or speakers may choose to use. Each move embodies "constituent elements" or "sub-moves" (also known as steps) and is characterized by some distinct linguistic features.

Rather than focusing on one field, some studies are also concerned with a number of disciplines. Gosden (1992) investigated the hard sciences - physics, chemistry, and biology; Holmes (1997) with three social sciences - history, political science, and sociology; Samraj (2002) with Wildlife Behavior and Conservation Biology; Ryvityte (2003) with medicine, economics, and linguistics; Lim (2011) with Applied Linguistics and Education. Peacock's (2002) studies dealt with a corpus of up to seven disciplines - Physics, Biology, Environmental Science, Business, Language \& Linguistics, Public and Social Administration, and Law from 252 RAs (1.4 million- word corpus), and in his latter (Peacock, 2011) with 8 disciplines from 288 RAs (with the addition of Chemistry).

More recently, with corpus linguistics, the number of disciplines, and along with it the number of texts, has tended to be larger. Of special interest is Cortes' (2013) investigation involving as many as 13 disciplines Agronomy, Applied Linguistics, Animal Science, Biology, Business, Chemistry, Civil and Materials Engineering, Communication Studies, Computer science, Economics, Physics and Astronomy, Statistics, Urban and Regional Planning. The most sophisticated in terms of size and methodology so far lies with the project conducted by Cotos et al (2017), who explored the Methods sections of a corpus of nine hundred texts representative of thirty academic fields. The analysis resulted in a comprehensive cross-disciplinary model, called Demonstrating Rigour and Credibility (DRaC). The model contains three moves and sixteen steps, which are defined in terms of functional and content realizations. DRaC further served as the analytic framework for corpus annotation. Additionally, the analytic framework allowed for intra- and crossdisciplinary comparisons and valuation by experts in the disciplines.

Overall, the findings show how RAs both draw upon and vary from the conventional Introduction - Method - Results - Discussion (IMRD) framework. It seems legitimate to accept that most RAs broadly reflect major aspects of the IMRD macro-structure (Brett, 1994; Holmes, 1997; Nwogu, 1997). These sections differ in terms of their primary communicative purposes, and this generally motivates the use of different section headings. 
Nonetheless, while there is little doubt that the IMRD and CARS models are commonly found to some extent in its pure form in many disciplines, many researchers have reported remarkable deviations in some cases. The most noticeable seems to lie with the RAs in Mathematics. Graves, Moghaddasi, and Hashim (2013)report the macro-organizational structure of RAs in mathematics, based on an analysis of 30 pure and applied mathematics articles. They show that Mathematics RAs do not follow the organizational pattern of the IMRD framework, but depart considerably from it for an Introduction-Results model to enable researchers to present new knowledge as clearly and succinctly as possible. Method section is notably absent due to the wellestablished methodology (deduction and induction) used in the field and Discussion section required to interpret research findings is relatively uncommon. Similarly, Posteguillo (1998) presents the results which indicate that the IMRD pattern cannot be applied to RAs in computer science systematically: while Introductory and Conclusion sections are used in most instances, it is the central part of these articles which seems to depart more from the IMRD pattern.

Another detailed presentation of key variations at the macro level comes in Yang \& Allison's (2004) work. They found the frequent occurrence of separate sections for Theoretical Basis, Literature Review, and Research Questions between Introduction and Method as well as a separate closing section of Pedagogic Implications, which represents noteworthy feature of the discipline of applied linguistics. The findings are consistent with Holmes (1997) on sociology and political science RAs. He reported the existence of an extensive section dealing with theoretical background, previous literature and general topical information after the Introduction section in political science and sociology RAs. The researchers argued that this could possibly be considered as a structural feature common among most social science RAs. The emphasis on theory as reflected in the macro-structure may be due to the lack of widely accepted consensus on some theories or concepts in the discipline. The authors in the social sciences are also more likely to recommend potential research directions more frequently than those in the hard sciences.

Regarding the lower levels, some studies following Swales' work on Moves and Steps have begun to find regular and systematic deviations in the patterns found in various disciplines. The RAs writers can choose to omit a particular Move or vary the order of Moves or Steps. The results of previous research indicate the existence of disciplinary variation, most notably between social sciences and hard sciences. For example, the employment of Recommending further studies varied in its frequency between hard and soft sciences. In hard science, its frequency was $40 \%$ in a Medical corpus (ElMalik \& Nesis's, 2008), $46.15 \%$ in a biochemistry corpus (Kanoksilapatham, 2005), and 58.82\% in a computer science corpus (Posteguillo, 1998). In soft science, the frequency of this step was as high as $70 \%$ study on applied linguistics (Amirian et al., 2008).

A very detailed presentation of disciplinary variation is Peacock's (2002). In an intensive study of a 1.4 million-word corpus, involving seven disciplines, Peacock (2002) reported that there were clear interdisciplinary differences in the number of moves and types of moves, and cycles of moves used. Particularly, the authors in Physics and Environmental Science made only around half of the moves found. There were also marked differences in the type of moves used in these two disciplines: referring to previous research, describing limitations, 
and making recommendations for further research were less common. Another clear disciplinary convention was that Background about theory is more frequent in Biology and Physics, and less frequent in Environmental Science and Language and Linguistics. Reference to previous research appeared to be more important in Language and Linguistics. The findings also revealed differences in the type of move cycles used. For example, the cycle unexpected outcome(s) + reason(s) for unexpected outcome(s) was very common in Biology, Physics, and Environmental Science but rare in the other four disciplines. Peacock (2002: 490-491) maintains,

It is not easy to explain these discipline differences. RA authors seek acceptance and appeal to their audience (editors and readers) to claim membership of their discourse community and face sanctions rejection and/or questioning of claims - if they step far outside discipline conventions. Much might depend on publication and peer acceptance, and the potential sanctions of rejected papers and claims may strongly motivate authors to follow discipline conventions."

The researchers concluded that the differences reflect rhetorical disciplinary constraints and that the patterns found are accepted within the particular disciplines as being the recognized way for writers to persuade readers of the validity of their data and conclusions (Peacock, 2002).

Kanoksilapatham (2005) reports a move which is claimed to be unique in biochemistry RAs. Basing on the results of a move analysis of 60 biochemistry RAs, the researcher identified Move Justifying procedures or methodology, which provides the rationale for the scientists' decision to use particular experimental methods, procedures, or techniques. This move can be expressed by two steps, which are either citing established knowledge of the procedure or referring to previous research. Kanoksilapatham (2005) also stated that her finding was consistent with that of Thompson (1993) who identified this move in $93.75 \%$ of 16 RAs analyzed. Another unique feature of biochemistry RAs is that both Contextualizing the study and Consolidating results are obligatory. According to the researcher, these features are emphasized due to "scientists' sensitivity to carefully situating their work in the interest of their discourse community; this allows the scientists' studies to be scrutinized with respect to their contributions to their field".

Not only across different disciplines are there differences in the organization of information but also across the sub-fields of a discipline variations can be noticeable. Dobakhti's (2016) study suggests that whether the research design is qualitative or quantitative influences the conventions and norms of RAs in Applied Linguistics. The paper reports that there are similarities and differences between the move structure of the Discussion section of qualitative RAs and that concerning empirical RAs. The most significant difference was the continuous reference of qualitative RA writers to their data. The analysis revealed one new move appearing after the writers stated their findings, in which the writers referred to their data to provide evidence and support their findings. Another new move found was Supporting the Explanation/Interpretation/ Evaluation/ Rejected Explanation where the writers provided evidence for their comments on findings by referring to their data and/or literature.

For more into disciplinary similarities and variations, a summary to contrast of the 
move/step schemas for the Methods section from some previous studies and the clusters of disciplines similar in the use of steps can be found in Cotos et al (2017).

\subsection{Linguistic features of moves/steps}

The linguistic features intertwined with the communicative functions of each move/ step were the focus of some early studies. It is pedagogically motivated because of the implication that certain key grammatical features are vital in ESP work and that other grammatical features of little relevance to ESP work can be ignored (Dudley-Evans, 2000).

A majority of research adopted the traditional terms and their analyses were mostly based on the descriptions of English usage presented by Quirk, Greenbaum, Leech and Svartvik (1985), Greenbaum and Quirk (1992), or Downing and Locke (1995). Swales (1990) analyzed the texts manually to identify linguistic features in the CARS model. For instance, Establishing a territory was realized by an evaluative statement of importance or interest to the field (such as it is well-known that...), time references to previous research (such as recently) and reporting verbs (such as show, claim). Lim (2006) conducted an analysis of the relationships between rhetorical categories and salient linguistic features in the Method section of the Management RAs. In a subsequent study, Lim (2010) identified the salient linguistic choices employed to comment in the Results section of applied linguistics and education RAs; for instance, Explaining the findings was characterized by the occurrence of reason adverbials (because, since...). Other studies focused on describing particular lexico-grammatical features such as distributions of noun phrases and hedging devices (ElMalik \& Nesi, 2008), tenses and first-person pronouns ( $\mathrm{Li} \& \mathrm{Ge}, 2009$ ), lexico-grammatical resources to argue and prove knowledge claims (Parkinson, 2011), or lexical choices and semantic categories of major word classes based on the work of Biber (2006) (Rahman et al, 2012). Similarly, using a corpus of management RAs, Lim (2008) examined how experienced writers use various rhetorical and linguistic strategies to accentuate the positive contributions of their research in the terminal portions of their papers. Prior studies in this vein have focused on the various linguistic resources that are used to display writer identity in RAs, such as hedges, epistemic modality, evaluative adjectives, and attitude markers.

Another line of research draws on Systemic Functional theory of language to investigate the relationship between language form and rhetorical function in RAs. These studies described the manipulation of marked theme (Gosden, 1992), unmarked theme, (Gosden, 1993), Transitivity system (Paltridge, 1993), or Thematic structure (Martinez, 2003). Gosden (1992) explores the potential for within-text structuring of marked themes and indicates that thematic flow can be predicted on the basis of the rhetorical goals in each section of RAs. Paltridge's (1993) analysis looked at the nature and structure of the transitivity system, the experiential system in terms of the process types, participants and circumstances involved in the individual clauses of the texts. Martinez (2003) analyzed the unmarked themes in the Methods section and the Discussions section of a corpus of 30 biology RAs. The study revealed differences in the thematic construction of the sections. The Method section was dominated by simple themes, realized by subjects that predominantly represented objects of the research. The few textual themes found were mainly temporal external themes. The simple themes of the Discussion were mainly realized by subjects that represented abstractions, particularly epistemic concepts. In this section, 
there was an important proportion of textual and interpersonal themes. The researcher attributed the differences to the different rhetorical purposes of the sections, which materialize in descriptive texts in the Method section and the argumentative texts in the Discussion section.

The salient linguistic features of RAs have also been captured from the phraseological patterns or lexical bundles theory with the employment of the corpus linguistic approach. Most notably, Cortes (2013) identified lexical bundles in the RA Introductions of thirteen disciplines. She further classified these bundles structurally and functionally to match to the moves and steps outlined in Swales's (2004) rhetorical framework of the Introduction. The results showed that a group of lexical bundles were exclusively linked to one move or step in a move while a second group occurred across several moves and steps. In addition, some of these expressions were "used to trigger the steps" calling for their use while others complemented other expressions and were used as comments. In this vein, Le and Harrison's (2015) paper provided a detailed account of how word clusters were used in three Steps of the Commenting on results Move: Interpreting results, Comparing results and Accounting for results in the Discussion section of quantitative research articles in the field of applied linguistics. The corpus linguistic approach was adopted to identify clusters in 124 Discussion texts from leading journals. A detailed description of the linguistic features, the internal structure and communicative functions of specific Steps were also presented based on the concordance analysis of the clusters. The findings further suggest that the use of specific clusters strongly manifests, and is conditioned by, the main communicative function of the Discussion section.

\subsection{The RAs from a cross-cultural perspective}

Also, studies on move-based analyses have been extended to compare the rhetorical moves and linguistic features of RAs in English with those in other languages, such as Chinese (Taylor \& Chen, 1991), Thai (Amnuai \& Wannaruk, 2013), Indonesian (Rahman et al, 2012), Turkish (Elvan Eda Is \& 1k-Tas, 2017), Spanish (Moreno, 1997, 1998), Lithuanian (Ryvityte, 2003), Sudanese (ElMalik \& Nesi, 2008), Iranian (Fazilatfar \& Naseri, 2014), Persian (Ershadi \& Farnia, 2015) or Malaysian (Ahmad, 1997).

Amnuai \& Wannaruk (2013) investigated the move structure of the Discussions section in English and Thai Applied Linguistics RAs. The findings displayed both similarities and differences regarding the move occurrence, move-ordering patterns, and move cyclicity. Similarly, Taylor and Chen (1991) found that Chinese scholars would hesitate to use Indicating a gap in their Introductions, which may be due to their perception of this move as fault-finding and potentially face-threatening to readers. Similarly, Ahmad (1997) found that Malaysian scholars tend to avoid this move. Ahmad (1997) maintained that if employed, this move is not to indicate the gap but to justify the need to conduct studies previously conducted in other countries but still unresearched in the local context. This move thus shows the vital role of socio-cultural factors in determining the rhetorical structure of RAs. Peacock's (2002) analysis unfolded various differences between native speakers' and non-native speakers' RAs in the number and type of moves and move cycles. The researcher also noted that they were "fairly sharply split along discipline lines". Native authors in Physics, Biology, and Environment Science made Claim of generalization arising from the results/ contribution to research 
more often than non-native authors. English native authors in Physics and Biology also made Limitation more often than non-native authors. In contrast, non-native authors in all three humanities (Business, Language and Linguistics, and Public and Social Administration) made Recommendations for future research much less often. Non-native authors in all three sciences had a much stronger tendency to use the move cycle [un] expected outcome + explanation than did native authors.

Equally detailed, Rahman et al (2012) report several differences in the Introduction between English and Indonesian RAs. At the macro level, the English RAs respectively have a higher proportion of Reviewing previous research, Indicating gap, and Summarizing methods. By contrast, their Indonesian counterparts use a greater deal with making topic generalizations, presenting positive justifications, and stating the value of the present research. Additionally, while the Indonesian RAs have more unidentified schematic elements and lack outlining the structure of paper, the English RAs display a larger proportion of move reiteration. At the micro level, while the English papers are featured with the strategies of selfmention, their Indonesian counterparts are characterized by the lack of self-mention. The researchers argued that these differences might be partially influenced by the writers' culture, knowledge, editorial policy, and social environment.

\section{Implications}

Space constraints precludes more details of the wealth of issues covered the literature relating to the RA genre in the past nearly four decades. It is nonetheless hoped that the synthesis is of practical significance to both
ESP and EAP pedagogy and to the practice of writing for international publication of the non-Anglophone novice scholars. With the implications provided below for future theoretical research and pedagogical intervention, we have a great deal to look forward notwithstanding this limitation.

Firstly, this review is confined to Swalesian' move/step-based generic structure, which exclusively delineates only four sections - Introduction, Method, Discussion, and Conclusion. The other constituent sections of RAs are not looked at this this present paper, such as the Abstracts, as a conventional obligatory section, and Highlights, as a novel periphery section of many academic promotion-oriented publications, which both feature the beginning of most articles (Khedri, Heng \& Ebrahimi, 2013; Pho, 2008b; Santos, 1996; Yang, 2016; amongst others). Thus, any comprehensive reviews of literature and empirical investigations on these important sections are highly essential to contribute to the present landscape of this field of study. A limitation to Swalesian's move-based framework in this paper also makes it impossible to cover any account of the equally successfully established model of generic analysis - the generic structure potential (GSP), fundamentally based within SFL. Hasan's (1984, 1989) GSP allows one to describe the possibilities of realization of any text type. Further syntheses and/or investigations of the RAs from this perspective must certainly yield rich insights.

Practically, although opponents to ESP undergraduates' genre-based writing courses tend to shed doubt on the effectiveness of decontextualized instruction of generic characteristic features in the classroom and the feasibility of transferring genre knowledge learned in the classroom to authentic writing tasks (Haneda \& Wells, 2000; Huang, 
2014), it is arguable that the RA genre be an indispensable component in disciplinespecific writing courses to L2 graduates and post-graduates in order to facilitate their endeavor to build their membership in their discourse community. A rhetorical knowledge of the schematic organization, moves, and steps can effectively help learners establish a repertoire of structures and become able to exploit these to meet their needs (Hyland, 2007; Huang, 2014; Rahman et al, 2012). The goal of genre-based learning may be not only the development of the awareness of generic features, but also the development of the considerations of the socio-cultural dimensions motivating the generic features. Knowledge of move structure and the associated communicative functions of moves/steps is clearly important for the teaching of ESP. Swales (1990) and many others describe the necessity of using the models as input to provide students with the discipline-specific move structure model. The findings of multiple previous studies reinforce the notion that move structure varies to some extent from discipline to discipline, so the teaching of academic writing will clearly need to reflect this variation. No single model can be considered entirely appropriate for learners in different academic disciplines. The teacher's task is also to assist students towards a command of lexico-grammatical patterns which typically occur in different Moves/ Steps through an awareness of target genres. Dudley-Evans (2000) lucidly brought this out,

It is clearly possible to use the generalized CARS model as the starting point for the teaching of academic writing, particularly if one is teaching heterogeneous groups of students from different disciplines, but with homogeneous groups it may be much more efficient to focus on the specific features of the actual genres that students actually have to read or write. This is especially the case where students are in an EFL situation studying their subject course in their first language. Such students will not have the high proficiency levels in English that most students have in a first or second language situation and will need, in my opinion, a much more straightforwardly linguistic approach based on the actual texts they use. They do not have the linguistic sophistication to deal with issues about the readership and the discourse community in any depth. They need to see how the Moves and Steps work in the genres they use and how they are expressed in English.

Besides, as writing is a socially developed skill, it is essential to address barriers in the socializing process that hinder novice NNES writers from becoming visible in international publication contexts (Is1k-Tas, 2018). Novice writers may lack basic familiarity with the conventionalized forms of scientific discourse (Cotos et al, 2017). Some researchers point out that genres can only be fully mastered through acquisition. This is a process to acquire the specific genres through natural exposure to their elements and interactions with the very discourse communities. According to Lim (2008), competence and readiness to write an academic genre normally come only after students have acquired sufficient experience in reading relevant texts; thus, order to achieve a level that can enable them to make independent interpretive judgments while writing, students need to study relevant texts prudently and critically through numerous background readings. These measures may 
present potential advantages for novice researchers in struggling with publishing in English-medium journals.

Finally, knowledge of the generic differences in different disciplines and cultures is pivotal in setting clear learning objectives and designing materials for ESP/ EAP students. The extent to which explicit pedagogy and rich immersion of the RAs can prove efficient to serve as "springboard for novices' understanding and use of genre discourse" (Hyland, 2007), undoubtedly, largely relies on further genre/move-based research into the RAs of students' target disciplines, as well those emerging from student's locally-oriented academic purposes, or those conditioned by students' socio-cultural contexts.

\section{References}

Ahmad, Ummul. (1997). Scientific research articles in Malay: a situated discourse analysis (Doctoral thesis). University of Michigan, Ann Arbor.

Amirian, Z., Kassaian, Z., \& Tavakoli, M. (2008). Genre analysis: an investigation of the discussion sections of applied linguistics research articles. The Asian ESP Journal, 4(1), 39-63.

Amunai, A., \& Wannaruk, A. (2013). Investigating move structure of English Applied Linguistics research: Article discussions published in international and Thai journals. English Language Teaching, 6(2), 1-13.

Bhatia, V.K. (1997). Introduction: genre analysis and world Englishes. World Englishes, 16(3), 313-319.

Brett, P. (1994). A genre analysis of the results section of sociology articles. English for Specific Purposes, 13, 47-59.

Cortes, V. (2013). The purpose of this study is to: Connecting lexical bundles and moves in research article introductions. English for Academic Purposes, 12(1), 33-43.

Cotos, E., Huffman, S., and Link, S. (2017). A move/step model for methods sections: Demonstrating Rigour and Credibility. English for Specific Purposes, 46, 90-106

Dobakhti, L. (2016). A genre analysis of discussion sections of qualitative research articles in applied linguistics. Theory and Practice in Language Studies, 6(7), 1383-1389.

Downing, A., \& Locke, P. (1995). A university course in English grammar. New York: Phoenix ELT.
Dudley-Evans, T. (2000). Genre analysis: A key to a theory of ESP. l bé rica, núm. 2, 3-11.

Dujsik, D. (2013). A Genre Analysis of Research Article Discussions in Applied Linguistics. Language Research, 49(2), 453-477.

ElMalik, A. T., \& Nesi, H. (2008). Publishing research in a second language: the use of Sudanese contributors to international medical journals. Journal of English for Specific Purposes, 7, 87-96.

Ershadi, S., \& Farnia, M. (2015). Comparative generic analysis of discussions of English and Persian computer research articles. Komunikacija I Kultura, Godina Vi, broj 6.

Fazilatfar, A. M., \& Naseri, Z. S. (2014). Rhetorical Moves in Applied Linguistics Articles and their Corresponding Iranian Writer Identity, International Conference on Current Trends in ELT. Procedia Social and Behavioral Sciences, 98, 489 - 498.

Flowerdew, J. (1999). Writing for scholarly publication in English: The case of Hong Kong. Journal of Second Language Writing, 8(2), 123-145. http:// dx.doi.org/10.1016/S1060-3743(99)80125-8

Gosden, H. (1992). Discourse functions of marked themes in scientific research articles. English for Specific Purposes, 11(3), 207-224.

Gosden, H. (1993). Discourse functions of subject in scientific research articles. Applied Linguistics, 14(1), 56-75.

Graves, H., Moghaddasi, S., \& Hashim, A. (2013). Mathematics is the method: Exploring the macroorganizational structure of research articles in mathematics. Discourse Studies, 15(4), 421-438.

Greenbaum, S. \& Quirk, R. (1992). A student's grammar of the English language. Harlow, Essex: Pearson Education Limited.

Haneda, M., \& Wells, G. (2000). Writing in knowledge building communities. Research in the Teaching of English, 34(3), 430-457.

Hasan, R. (1984). The nursery tale as a genre. Nottingham Linguistics Circular, 13, 71-102.

Hasan, R. (1989). The structure of text. In M. A. K. Halliday \& R. Hasan (Eds.), Language, Context and Text: Aspects of Language in a Social-semiotic Perspective (pp. 52-69). Oxford: Oxford University Press.

Holmes, R. (2000). Variation and text structure: The discussion section in economics research articles. ITL: Review of Applied Linguistics, 107-135.

Holmes, R. (1997). Genre analysis and the social sciences: An investigation of the structure of research article discussion sections in three disciplines. English for Specific Purposes, 16(4), 321-337.

Huang, J. C. (2010). Publishing and learning writing for publication in English: perspectives of NNES PhD students in science. Journal of English for Academic Purposes, 9, 33-44.

Huang, J. C. 2014. Learning to write for publication in English through genre-based pedagogy: A case in 
Taiwan. System, 45, 175-186.

Hyland, K. (1996). Writing without conviction? Hedging in science research articles. Applied Linguistics, 17(4), 433-454.

Hyland, K. (2003). Genre-based pedagogies: A social response to process. Journal of Second Language Writing, 12, 17-29.

Hyland, K. (2002). Options of identity in academic writing. ELT Journal, 56(4), 351-358.

Hyland, K. (2007). Genre pedagogy: Language, literacy and L2 writing instruction. Journal of Second Language Writing, 16, 148-164.

Is1k-Tas, E. E. (2018). Authorial identity in Turkish language and English language research articles in Sociology: The role of publication context in academic writers' discourse choices. English for Specific Purposes, 49, 26-38.

Jaroongkhongdach, W., Todd, W., Keyuravong, S., \& Hall, D. (2012). Differences in quality between Thai and international research articles in ELT. Journal of English for Academic Purposes, 11, 194- 209.

Kanoksilapatham, B. (2005). Rhetorical structure of biochemistry research articles. English for Specific Purposes, 24(3), 269-292.

Kanoksilapatham, B. (2011). Civil Engineering Research Article Introductions: Textual Structure and Linguistic Characterisation. The Asian ESP Journal, 7(2), 55-84.

Khedri, M., Heng, C. S., \& Ebrahimi, S. F. (2013). An exploration of interactive metadiscourse markers in academic research article abstracts in two disciplines. Discourse Studies, 15(3), 319-331.

Kwan, B. S. C. (2017). A cross-paradigm macrostructure analysis of research articles in Information Systems. English for Specific Purposes, 45, 14-30.

Le, T. N. P., \& Harrington, M. (2015). Phraseology used to comment on results in the Discussion section of applied linguistics quantitative research articles. English for Specific Purposes, 39, 45-61.

Li, L., \& Ge, G. (2009) Genre analysis: Structural and linguistic evolution of the English-medium medical research article (1985-2004). English for Specific Purposes, 28, 93-104.

Li, Y. Y. (2007). Apprentice scholarly writing in a community of practice: an intraview of an NNES graduate student writing a research article. TESOL Quarterly, 41(1), 55-79.

Lim, J. (2006). Method sections of management research articles: A pedagogically motivated qualitative study. English for Specific Purposes, 25, 282-309.

Lim, J. (2010). Commenting on research results in applied linguistics and education: A comparative genre-based investigation. Journal of English for Academic Purposes, 9, 280-294.

Lim, J. (2011). 'Paving the way for research findings': Writers' rhetorical choices in education and applied linguistics. Discourse Studies, 13(6), 725-749.

Lim. J. (2008). Indicating Significance of Current Research: Pedagogical Implications of a Genre Analysis for Dissertation Writing. The Open Applied Linguistics Journal, 1, 46-55.

Mahzari, A., \& Maftoon, P. (2007). A contrastive study of the introduction section of English and Persian medical research articles. Iranian Journal of Language Studies (IJLS), 1(3), 201-214.

Martínez, I. (2003). Aspects of theme in the method and discussion sections of biology journal articles in English. Journal of English for Academic Purposes, 2, 103-123.

Moreno, A.I. (1997). Genre constraints across languages: causal metatext in Spanish and English RAs. English for Specific Purposes, 16(3), 161-179.

Nwogu, K. N. (1997). The medical research paper: structure and functions. English for Specific Purposes, 16(2), 119-138.

Ozturk, I. (2007). The textual organisation of research article introductions in applied linguistics: Variability within a single discipline. English for Specific Purposes, 26, 25-38.

Paltridge, B. (1993). Writing up research: a systemic functional perspective. System, 21(2), 175-192.

Parkinson, J. (2011). The discussion section as argument: The language used to prove knowledge claims. English for Specific Purposes, 30, 164-175.

Peacock, M. (2002). Communicative moves in the discussion section of research articles. System, 30(4), 479-497.

Peacock, M. (2011). The structure of the Methods section in research articles across eight disciplines. Asian ESP Journal, 7(2). 97-124.

Pho, P.D. (2008a). How can learning about the structure of research articles help international students? Paper presented at The 19th International ISANA International Education Conference, Auckland, New Zealand.

Pho, P. D. (2008b). Research article abstracts in applied linguistics and educational technology: a study of linguistic realizations of rhetorical structure and authorial stance. Discourse Studies, 10(2), 231-250.

Posteguillo, S. (1998). The schematic structure of computer science research articles. English for Specific Purposes, 18(2), 139-160.

Quirk, R., Greenbaum, S., Leech, G. \& Svartvik, J. (1985). A comprehensive grammar of the English language. London: Longman Group Limited.

Rahman, K., Mataram, I., Sofwan, A., (2012). The schematic structure of English and Indonesian research article introductions. Journal of Language and Literature, 7(1), 13-31.

Ryvityte, B. (2003). Research article introductions: variations across disciplines and cultures. Kalbotyra, 53(3), 93-100.

Samraj, B. (2002). Introductions in research articles: variation across disciplines. English for Specific 
Purposes, 21, 1-17.

Santos, M. B. D. (1996). The textual organization of research paper abstracts in applied linguistics. Text, 16(4), 481-499..

Swales, J.M. (1981/1990). Genre Analysis: English in academic and research settings. Cambridge: Cambridge University Press.

Swales, J.M. (2004). Research genres: exploration and applications. Cambridge: Cambridge University Press.

Taylor, G., \& Chen, T. (1991). Linguistic, cultural, and subcultural issues. Applied Linguistics, 12, 319-336.

Tessuto, G. (2015). Generic structure and rhetorical moves in English-language empirical law research articles: Sites of interdisciplinary and interdiscursive cross-overs. English for Specific Purposes, 37, 13-26.
Thompson, D. K. (1993). Arguing for experimental 'fact' in science: a study of research article results sections in Biochemistry. Written Communication, 10(1), 106-128.

Yang, R. \& Allison, D. (2003). Research articles in applied linguistics: moving from results to conclusions. English for Specific Purposes, 22, 365-385.

Yang, R. \& Allison, D. (2004). Research articles in applied linguistics: structures from a functional perspective. English for Specific Purposes, 23, 264-279.

Yang, W. (2016). Evaluative language and interactive discourse in journal article highlights. English for Specific Purposes, 42, 89-103.

\title{
TÌM HIỂU VỀ CÔNG BỐ QUỐC TẾ: TỔNG QUAN NGHIÊN CỨU VỀ BÀI BÁO KHOA HỌC THEO MÔ HİNH PHÂN TÍCH CÁC BƯỚC
}

\author{
Tôn Nữ Mỹ Nhật \\ Khoa Ngoại ngư, Trương Đại học Quy Nhơn, \\ 170 An Dưong Vurong, Tp. Quy Nhơn, Bình Định, Việt Nam
}

Tóm tắt: Bắt đầu từ công trình nền móng của Swales (1981/1990) về bài báo khoa học, thể loại này đã được nghiên cứu sâu rộng trong hơn 3 thập niên qua. Thực tế này xuất phát từ tầm quan trọng trong vai trò trao đổi kiến thức học thuật của các bài báo khoa học, và cũng từ yêu cầu công bố quốc tế được đặt ra cho giới học thuật ở các nước mà tiếng Anh không phải là bản ngũ̃. Bài báo này trình bày những khía cạnh thiết yếu của các bài báo quốc tế trong nhiều chuyên ngành khác nhau, được tổng hợp từ các công trình nghiên cứu về thể loại này dựa trên mô hình phân tích các bước thoại của Swales. Bài báo tập trung vào (1) cấu trúc diễn đạt và các mục đích giao tiếp, (2) các đặc trưng ngữ pháp - từ vựng của các bước thoại, và (3) những so sánh đối chiếu 2 khía cạnh này giữa các bài báo quốc tế bằng tiếng Anh và bằng các ngôn ngữ khác.

Từ khóa: bài báo khoa học, phân tích thể loại, phân tích bước thoại, công bố quốc tế 